\title{
Magnesium supplementation and high volume hydration reduce the renal toxicity caused by cisplatin-based chemotherapy in patients with lung cancer: a toxicity study
}

Takako Oka ${ }^{1+}$, Tatsuo Kimura ${ }^{1,2^{*}+}$, Tomohiro Suzumura ${ }^{3}$, Naoki Yoshimoto ${ }^{1}$, Toshiyuki Nakai ${ }^{1}$, Norio Yamamoto ${ }^{1}$, Kuniomi Matsuura', Shigeki Mitsuoka ${ }^{4}$, Naruo Yoshimura ${ }^{4}$, Shinzoh Kudoh ${ }^{1}$ and Kazuto Hirata ${ }^{1}$

\begin{abstract}
Background: Renal toxicity is a clinical problem that affects $28-42 \%$ of patients undergoing treatment with cisplatin. Renal toxicity can be minimized by high volume hydration with mannitol diuresis. Recent reports have shown that cisplatin induces depletion of $\mathrm{Mg}$ and that $\mathrm{Mg}$ supplementation can reduce renal toxicity. We hypothesized that Mg infusion combined with low volume hydration may not be sufficient to overcome cisplatin-induced renal toxicity.

Methods: In total, 85 patients with lung cancer receiving their first cycle of cisplatin-based chemotherapy at the Osaka City University Hospital were classified into three groups: those administered high volume hydration without Mg infusion (high-volume Mg-), high volume hydration with Mg infusion (high-volume Mg+), and with low volume hydration with Mg infusion (low-volume $\mathrm{Mg}+$ ). Serum creatinine $(\mathrm{s} C \mathrm{r}$ ) and creatinine clearance (CrCl) were examined before and after treatment with cisplatin. Multivariable analysis was carried out to identify the most important contributing factors.

Results: There were no significant differences in pre-treatment s $\mathrm{Cr}$ levels or $\mathrm{CrCl}$ between groups. In the high-volume Mg- group, post-treatment sCr significantly increased compared with pre-treatment levels, while post-CrCl significantly decreased compared with pre-treatment $\mathrm{CrCl}(p<0.001$ and $p<0.001$, respectively). In the high-volume Mg+ group, there was no significant difference between pre- and post-treatment levels of $\mathrm{s} C r$, or between pre- and post-treatment $\mathrm{CrCl}(p=0.118$ and $p=0.254$, respectively). In the low-volume $\mathrm{Mg}+$ group, there was a trend towards increased $\mathrm{sCr}$ levels and decreased $\mathrm{CrCl}$ after treatment $(p=0.068$ and $p=0.055$, respectively). Multivariate analysis revealed that the absence of Mg infusion and low-volume hydration were both independent factors for decreased $\mathrm{CrCl}(p<0.001$ and $p=0.001$, respectively).
\end{abstract}

Conclusions: High-volume hydration and Mg infusion reduces the renal toxicity induced by cisplatin. A low-volume $\mathrm{Mg}+$ regimen may be considered for patients with adequate renal function. Trial Registration: Observational Study UMIN000013950; Registered 13 May 2014

Keywords: Magnesium, Low volume hydration, Cisplatin, Lung cancer

\footnotetext{
* Correspondence: kimutats@med.osaka-cu.ac.jp

${ }^{\dagger}$ Equal contributors

'Department of Respiratory Medicine, Graduate school of Medicine, Osaka

City University, 1-4-3 Asahi-machi, Abeno-ku, Osaka 545-8585, Japan

${ }^{2}$ Department of Premier Preventive Medicine, Graduate school of Medicine,

Osaka City University, 1-1-43 Abenosuji, Abeno-ku, Osaka 545-6090, Japan

Full list of author information is available at the end of the article
} 


\section{Background}

The mortality rate associated with lung cancer is increasing worldwide. In fact, lung cancer (along with tracheal and bronchial cancers) was responsible for 1.5 million (2.7\%) deaths in 2011, compared with 1.2 million (2.2\%) deaths in 2000, according to the World Health Organization. In more than $60 \%$ of patients with lung cancer, particularly those with non-small cell lung cancer (NSCLC), the cancer is inoperable at the time of diagnosis and requires chemotherapy [1].

Cisplatin is one of the most important components of standard therapies for lung cancer and is also an effective adjuvant for chemotherapy and chemoradiotherapy [2]. Renal toxicity is a well-known adverse effect of cisplatin treatment, which limits its use. Despite intensive prophylactic measures, renal toxicity still affects a large proportion of patients treated with cisplatin, and a significant decrease in glomerular filtration rate is commonly observed during treatment [3]. In 1977, Cvitkovic et al. reported that cisplatin-induced renal toxicity could be avoided with substantial hydration and mannitol-induced diuresis [4]. Subsequently, clinical trials were initiated in several types of cancers, including epidermoid carcinoma, ovarian adenocarcinoma, germ cell tumors of the testis, and metastatic melanoma [5,6]. Hayes et al. reported about patients who had been pre-hydrated intravenously with $2,000 \mathrm{ml}$ of $5 \%$ glucose in one-half normal saline over $12 \mathrm{~h}$, and post-hydrated with $1,200 \mathrm{ml}$ of one-half normal saline over $6 \mathrm{~h}$. Mannitol was infused (50 $\mathrm{ml}$ of $25 \%$ mannitol) as an intravenous bolus just before the administration of cisplatin, and was continuously infused $(300 \mathrm{ml}$ of $20 \%$ mannitol) for $6 \mathrm{~h}$ after the administration of cisplatin [6]. Even if cisplatin was approved in 1984 for use in Europe and the United States, nephrotoxic damage still affects $28-42 \%$ of patients treated with cisplatin [7].

To date, a number of studies have investigated strategies for prevention of cisplatin-induced renal toxicity. As free cisplatin causes renal toxicity, shortening the free cisplatin and renal tubular contact time is important to reduce its nephrotoxicity [8]. As more than $90 \%$ of free cisplatin binds to plasma proteins within $4 \mathrm{~h}$, hydration within that time after initiating treatment is a critical factor in reducing toxicity [8]. In addition, previous reports have demonstrated that cisplatin-induced $\mathrm{Mg}$ depletion may occur in some patients [9]. Willox et al. revealed that supplementation with $16 \mathrm{mEq} \mathrm{Mg}$ was beneficial in reducing renal tubular damage in patients with testicular cancer receiving cisplatin [10], while Bodnar et al. demonstrated that $40 \mathrm{mEq} \mathrm{Mg}$ supplementation had nephroprotective effects during chemotherapy with cisplatin in patients with epithelial ovarian cancer [7]. Muraki et al. showed that hydration with $8 \mathrm{mEq} \mathrm{Mg}$ and mannitol without furosemide prevents the nephrotoxicity induced by cisplatin and pemetrexed in patients with advanced
NSCLC [11]. Hirai, et al. also showed that $20 \mathrm{mEq} \mathrm{Mg}$ supplementation may be beneficial in preventing cisplatininduced nephrotoxicity in patients with esophageal or hypopharyngeal cancer [12]. Yoshida et al. reported that $8 \mathrm{mEq} \mathrm{Mg}$ preloading before cisplatin administration significantly reduced cisplatin-induced nephrotoxicity in 496 patients with thoracic malignancies [13]. Therefore, $\mathrm{Mg}$ supplementation, in addition to hydration, may also reduce the renal toxicity induced by cisplatin. Therefore, $\mathrm{Mg}$ supplementation is being considered an option for cisplatin-based chemotherapy. Prospective studies since 2007 have examined the use of low-volume hydration in combination with $\mathrm{Mg}$ supplementation. Tiseo, et al. demonstrated that low-volume hydration with $16 \mathrm{mEq} \mathrm{Mg}$ supplementation in cisplatin-based chemotherapy led to no increase in creatinine in only $35.3 \%$ of patients [14]. Hotta et al. reported that low-volume hydration $(2,500 \mathrm{ml})$ with $4 \mathrm{mEq} \mathrm{Mg}$ supplementation before and after cisplatin administration was associated with slightly worse renal toxicity during all cycles of chemotherapy, without significance [15]. Horinouchi et al. examined the safety of low-volume hydration $(1,550-2,050 \mathrm{ml})$ with $8 \mathrm{mEq} \mathrm{Mg}$ supplementation; however, renal function during all courses of cisplatin administration was slightly worse [2]. However, few studies have compared the renal toxicities associated with treatment using high-volume hydration with $\mathrm{Mg}$ supplementation to those associated with treatment using low-volume hydration with $\mathrm{Mg}$ supplementation. We hypothesized that $\mathrm{Mg}$ infusion may not be sufficient to overcome the renal toxicity caused by cisplatin during low-volume hydration. Therefore, we performed a historical prospective cohort study wherein patients were classified into three groups: high-volume hydration without $\mathrm{Mg}$ infusion, high-volume hydration with $\mathrm{Mg}$ infusion, and low-volume hydration with $\mathrm{Mg}$ infusion.

\section{Methods \\ Patients}

This study was reported according to the STROBE guidelines [16]. The chemotherapy procedure was explained and informed consent was obtained from all patients before treatment. The $\mathrm{Mg} /$ hydration protocols were approved by the Institutional Review Board (No. 1402) of Osaka City University Hospital in accordance with the Declaration of Helsinki.

The renal toxicity in patients with lung cancer receiving their first cycle of cisplatin-based chemotherapy at the Osaka City University Hospital between December 2011 and October 2013 were included in the present study. Patients were placed into three groups, and renal toxicity was compared before and after cisplatin-based chemotherapy. In our hospital, until December 2012, we performed conventional high-volume hydration without $\mathrm{Mg}$ infusion in patients undergoing cisplatin-based chemotherapy 
(high-volume Mg-). In December 2012, we initiated the administration of $\mathrm{Mg}$ sulfate during the pre-hydration stage (high-volume $\mathrm{Mg}+$ ). Subsequently, the new low-volume hydration with $\mathrm{Mg}$ infusion regimen was initiated in July 2013 (low-volume Mg+). We investigated patient characteristics including age, sex, body surface area, performance status, stage, histology, serum hemoglobin, serum albumin, serum creatinine $(\mathrm{sCr})$, creatinine clearance $(\mathrm{CrCl})$, cisplatin dose, regular use of non-steroid anti-inflammatory medicines, regular use of $\mathrm{Mg}$-containing medications for purgative, and combined anticancer agents.

\section{Treatments}

All patients received combination chemotherapy of cisplatin and another cytotoxic agent (i.e. vinorelbine, pemetrexed, irinotecan, etoposide, gemcitabine, S-1, amrubicin, or docetaxel). Table 1 shows an example of the chemotherapy hydration regimen in each group. In the high-volume Mg- and high-volume $\mathrm{Mg}+$ groups, patients were administered a total of $3,550 \mathrm{ml}$ of electrolytecontaining solutions that contained normal saline and one-quarter saline solution Soldem 3A (Terumo, Tokyo, Japan) on day 1 and $950 \mathrm{ml}$ of the solutions on days 2 and 3. A total of $600 \mathrm{ml}$ of $20 \%$ mannitol and furosemide (20 mg) was administered as enforced diuresis on day 1 , and $300 \mathrm{ml}$ of $20 \%$ mannitol was administered on days 2 and 3. Antiemetic agents (dexamethasone [6.6 mg] and granisetron $[3 \mathrm{mg}]$ ) were infused on days $1-3$. Cisplatin, which was dissolved in $300 \mathrm{ml}$ of normal saline solution, was infused over $90 \mathrm{~min}$. In the low-volume $\mathrm{Mg}+$ group, patients were administered a total of 2,200 ml of electrolyte-containing solutions on day 1 with no infusions on days 2 and 3; instead, they were administered 2,000 ml of water per os on day 1 and $1,000 \mathrm{ml}$ of water on days 2

Table 1 An example of the chemotherapy hydration regimen for each group

\begin{tabular}{|c|c|c|c|c|c|c|c|}
\hline & & High-volume hydration & Mg- & High-volume hydration & $\mathrm{Mg}+$ & Low-volume hydration $\mathrm{Mg}+$ & \\
\hline & & & $\mathrm{ml}$ & & $\mathrm{ml}$ & & $\mathrm{ml}$ \\
\hline Day 1 & & N.S. & 50 & N.S. & 50 & N.S. & 50 \\
\hline & Antiemetics & & & & & N.S. & 100 \\
\hline & & Granisetoron 3 mg & 100 & Granisetoron 3 mg & 100 & $\begin{array}{l}\text { Fosaprepitant meglumine } \\
150 \mathrm{mg}\end{array}$ & \\
\hline & & Dexamethasone 6.6 mg & 2 & Dexamethasone $6.6 \mathrm{mg}$ & 2 & N.S. & 50 \\
\hline & & & & & & Palonosetoron $0.75 \mathrm{mg}$ & 5 \\
\hline & & & & & & Dexamethasone 9.9 mg & 2 \\
\hline & Other cytotoxic agent & $\begin{array}{l}\text { N.S. with other } \\
\text { cytotoxic agent }\end{array}$ & 500 & $\begin{array}{l}\text { N.S. with other } \\
\text { cytotoxic agent }\end{array}$ & 500 & N.S. with other cytotoxic agent & 100 \\
\hline & Pre-hydration & N.S. & 500 & N.S. & 500 & $1 / 4$ saline solution & 500 \\
\hline & & 1/4 saline solution & 500 & 1/4 saline solution & 500 & $\mathrm{MgSO}_{4} 8 \mathrm{mEq}$ & \\
\hline & & & & $\mathrm{MgSO}_{4} 8 \mathrm{mEq}$ & & & \\
\hline & Diuresis & & & 20\% Mannitol & 300 & 20\% Mannitol & 300 \\
\hline & Cisplatin & N.S. with cisplatin & 300 & N.S. with cisplatin & 300 & N.S. with cisplatin & 100 \\
\hline & Post-hydration & N.S. & 500 & N.S. & 500 & N.S. & 500 \\
\hline & Diuresis & 20\% Mannitol & 300 & & & & \\
\hline & Post-hydration & $1 / 4$ saline solution & 500 & 1/4 saline solution & 500 & 1/4 saline solution & 500 \\
\hline & Diuresis & 20\% Mannitol & 300 & 20\% Mannitol & 300 & & \\
\hline & & Frosemide $20 \mathrm{mg}$ & 2 & Frosemide $20 \mathrm{mg}$ & 2 & & \\
\hline & Oral hydration & & 0 & & 0 & & 2,000 \\
\hline Day 2,3 & & N.S. & 50 & N.S. & 50 & & \\
\hline & Antiemetics & Granisetoron $3 \mathrm{mg}$ & 100 & Granisetoron 3 mg & 100 & & \\
\hline & & Dexamethasone 6.6 mg & 2 & Dexamethasone $6.6 \mathrm{mg}$ & 2 & & \\
\hline & Hydration & 1/4 saline solution & 500 & 1/4 saline solution & 500 & & \\
\hline & Diuresis & 20\% Mannitol & 300 & 20\% Mannitol & 300 & & \\
\hline & Oral hydration & & 0 & & 0 & & 1,000 \\
\hline & Total infusion & Day 1 & 3,550 & Day 1 & 3,550 & Day 1 & 2,200 \\
\hline & & Day 2,3 & 950 & Day 2,3 & 950 & Day 2,3 & 0 \\
\hline
\end{tabular}

N.S., normal saline. 
and 3. A total of $300 \mathrm{ml}$ of $20 \%$ mannitol was infused before cisplatin administration on day 1. Antiemetic agents (fosaprepitant meglumine $[150 \mathrm{mg}]$, dexamethasone [6.6 mg], and palonosetron [0.75 mg]) were administered on day 1. Cisplatin, which was dissolved in $100 \mathrm{ml}$ of normal saline solution, was administered over $45 \mathrm{~min}$. In the high- and low-volume $\mathrm{Mg}+$ groups, $\mathrm{Mg}$ sulfate was administered before cisplatin in one-quarter saline solution. The dose of Mg sulfate was $8 \mathrm{mEq}$ based on previous reports $[2,11]$. Blood chemistry was analyzed twice a week during treatment. The chemotherapy procedure was explained and informed consent was obtained from all patients. Since this was a historical prospective cohort study, the difference from the previous $\mathrm{Mg}$ - protocol was explained to patients in high volume $\mathrm{Mg}+$ group, and the patients in low volume $\mathrm{Mg}+$ group were informed about the difference from the previous high volume $\mathrm{Mg}+$ protocol.

\section{Renal function and gastrointestinal toxicity}

Changes in $\mathrm{sCr}$ and gastrointestinal toxicity/anorexia were assessed using Common Terminology Criteria for Adverse Events Version 4.0 (CTCAE v4.0). sCr was measured just before chemotherapy (pre-sCr), twice a week during treatment, and on the last day of the first cycle of chemotherapy (post-s $\mathrm{Cr}$ ). $\mathrm{CrCl}$ was calculated using the Cockcroft-Gault formula: $\mathrm{CrCl}$ $[\mathrm{ml} / \mathrm{min}]=(140-$ age [years] $\times$ weight $[\mathrm{kg}]) \times 0.85$ [if female $] /(72 \times \mathrm{sCr}[\mathrm{mg} / \mathrm{dl}]) . \Delta \mathrm{sCr}$ was calculated using the formula: $\Delta \mathrm{sCr}[\mathrm{mg} / \mathrm{dl}]=(\mathrm{sCr}[\mathrm{mg} / \mathrm{dl}]$ after chemotherapy) $-(\mathrm{sCr}[\mathrm{mg} / \mathrm{dl}]$ before chemotherapy). $\Delta \mathrm{CrCl}$ was calculated using the formula: $\Delta \mathrm{CrCl}[\mathrm{ml} / \mathrm{min}]=$ $(\mathrm{CrCl}[\mathrm{ml} / \mathrm{min}]$ before chemotherapy $)-(\mathrm{CrCl}[\mathrm{ml} / \mathrm{min}]$ after chemotherapy).

\section{Statistical analysis}

Chi-square and Fisher's exact tests were used for categorical comparisons of data. Differences in the means of continuous measurements were tested with a Student's t-test and the Mann-Whitney $U$ test. The paired $t$-test and Wilcoxon matched-pairs signed-rank test was used for paired continuous measurements. The influence of the following factors on changes in $\mathrm{CrCl}$ were investigated on univariate analysis: age, sex, performance status, serum albumin, cisplatin dose, regular use of non-steroid anti-inflammatory medicines, regular use of Mg-containing purgatives, $\geq$ grade 2 anorexia, Mg infusion, and low-volume hydration. All of the factors were then included in a multiple linear regression model to identify contributing factors. P values $<0.05$ were considered statistically significant. All statistical analyses were performed with the statistical package Stata 12 for Windows.

\section{Results}

\section{Patient characteristics}

A total of 89 patients were enrolled. Four patients whose complications or medical histories may have affected their renal function were excluded; these included cases of a carcinoma of unknown primary, nephrotic syndrome, renal cancer, and a patient who received an inadequate amount of $\mathrm{Mg}$ sulfate. Eighty-one patients had lung cancer, while the remaining had thymic and bronchial cancers. Forty-one patients were included in the highvolume $\mathrm{Mg}$ - group, 27 in the high-volume $\mathrm{Mg}+$ group, and 17 in the low-volume $\mathrm{Mg}+$ group. Table 2 shows the characteristics of the 85 eligible patients. There were no significant differences in clinical and pathological parameters between the three groups. We analyzed the number of chemotherapy cycles and major reasons for treatment discontinuation (Additional file 1: Table S1). In the highvolume Mg- group, the most common event leading to discontinuation was renal toxicity $(n=9,[22 \%])$, followed by generalized weakness $(n=5,[12 \%])$. On the other hand, in the high- and low-volume $\mathrm{Mg}+$ groups, it was seen that none and 1 patient, respectively, discontinued cisplatin treatment due to renal toxicity. The reasons for discontinuation in these groups were other adverse reactions, switching to another regimen, and cancer progression.

\section{Renal toxicity}

Table 3 shows the maximum grade of $\mathrm{sCr}$ increase in each group. In the high-volume Mg- group, the grade was significantly higher than that in the high- and low-volume $\mathrm{Mg}+$ groups $(\mathrm{p}<0.001$ and $\mathrm{p}=0.02$, respectively). Grade 1 renal toxicity was seen in $96.3 \%$ and $88.2 \%$ of patients in the high- and low-volume $\mathrm{Mg}+$ groups, respectively. Next, we examined the recovery of $\mathrm{sCr}$ and $\mathrm{CrCl}$ after cisplatin treatment. Table 4 shows the comparison between pre- and post-treatment values of $\mathrm{sCr}$ and $\mathrm{CrCl}$ in each group. No significant differences in $\mathrm{sCr}$ or $\mathrm{CrCl}$ were present between the three groups before treatment. In the high-volume $\mathrm{Mg}$ - group, post-sCr significantly increased compared with pre-sCr, while post- $\mathrm{CrCl}$ significantly decreased compared to pre- $\mathrm{CrCl}(\mathrm{p}<0.001$ and $\mathrm{p}<0.001$, respectively). In the high-volume $\mathrm{Mg}+$ group, there was no significant difference between pre- and post-sCr levels or between pre- and post- $\mathrm{CrCl}(\mathrm{p}=0.118$ and $\mathrm{p}=0.254$, respectively). In the low-volume $\mathrm{Mg}+$ group, there was a trend towards an increase in post-s $\mathrm{Cr}$ compared with pre-sCr levels, and a trend towards a decrease in post- $\mathrm{CrCl}$ compared to pre- $\mathrm{CrCl}(\mathrm{p}=0.068$ and $\mathrm{p}=0.055$, respectively). Figure 1 shows the comparison of $\Delta \mathrm{sCr}$ and $\Delta \mathrm{CrCl}$ between treatment groups. The $\Delta \mathrm{sCr}$ in the highvolume $\mathrm{Mg}$ - group (median, $0.15 \mathrm{mg} / \mathrm{dl}$; interquartile range, 0.06 to $0.46 \mathrm{mg} / \mathrm{dl}$ ) was significantly higher compared with $\Delta \mathrm{sCr}$ in the high-volume $\mathrm{Mg}+$ (median, $0.03 \mathrm{mg} / \mathrm{dl}$; interquartile range, -0.03 to $0.06 \mathrm{mg} / \mathrm{dl}$ ) and 
Table 2 Patient characteristics

\begin{tabular}{|c|c|c|c|}
\hline & $\begin{array}{l}\text { High volume hydration } \mathrm{Mg}- \\
(\mathrm{n}=41)\end{array}$ & $\begin{array}{l}\text { High volume hydration } \mathrm{Mg}+ \\
(\mathrm{n}=27)\end{array}$ & $\begin{array}{l}\text { Low volume hydration } \mathrm{Mg}+ \\
(\mathrm{n}=17)\end{array}$ \\
\hline Age (year) & 66 (63 to 70$)$ & 66 (57 to 70) & 63 (62 to 67$)$ \\
\hline Gender Male (\%) & $31(75.6)$ & $18(66.6)$ & $16(94.1)$ \\
\hline $\mathrm{BSA}\left(\mathrm{m}^{2}\right)$ & $1.7 \pm 0.2$ & $1.6 \pm 0.2$ & $1.7 \pm 0.2$ \\
\hline PS (ECOG): 0 (\%) & $5(12.1)$ & $4(14.8)$ & $5(29.4)$ \\
\hline $1(\%)$ & $36(87.8)$ & $23(85.2)$ & $12(70.6)$ \\
\hline Stage I (\%) & $0(0)$ & $1(3.7)$ & $0(0)$ \\
\hline II (\%) & $5(12.2)$ & $3(11.1)$ & $3(17.6)$ \\
\hline III (\%) & $25(61.0)$ & $15(55.5)$ & $8(47.1)$ \\
\hline IV (\%) & $9(22.0)$ & $7(25.9)$ & $6(35.3)$ \\
\hline Others (\%) & $2(4.9)$ & $1(3.7)$ & $0(0)$ \\
\hline Histology Adenocarcinoma (\%) & $17(41.5)$ & $13(48.1)$ & $11(64.7)$ \\
\hline Squamous cell carcinoma (\%) & $11(26.8)$ & $7(25.9)$ & $5(29.4)$ \\
\hline Small cell carcinoma (\%) & $9(22.0)$ & $6(22.2)$ & $1(5.9)$ \\
\hline Others (\%) & $4(9.8)$ & $1(3.7)$ & $0(0)$ \\
\hline Serum Hb (g/dl) & 13.3 (12.0 to 14.8$)$ & $13.6(12.8$ to 14.8$)$ & $13.3(12.7$ to 14.9$)$ \\
\hline Serum Alb (g/dl) & $4.0 \pm 0.4$ & $4.1 \pm 0.4$ & $3.9 \pm 0.4$ \\
\hline Cisplatin dose $\left(\mathrm{mg} / \mathrm{m}^{2}\right)$ & 80 (80 to 80$)$ & 80 (75 to 80$)$ & 80 (75 to 80$)$ \\
\hline \multicolumn{4}{|l|}{ Regular use drug } \\
\hline NSAIDs (\%) & $10(24.4)$ & $2(7.4)$ & $2(11.7)$ \\
\hline Mg for purgative (\%) & $14(34.1)$ & $8(29.6)$ & $5(29.4)$ \\
\hline \multicolumn{4}{|l|}{ Combined anticancer agent (\%) } \\
\hline VNB & $22(53.7)$ & $13(48.1)$ & $10(58.8)$ \\
\hline PEM & $3(7.3)$ & $6(22.2)$ & $5(29.4)$ \\
\hline CPT-11 & $3(7.4)$ & $1(3.7)$ & 0 \\
\hline VP-16 & $8(19.5)$ & $6(22.2)$ & $1(5.9)$ \\
\hline GEM & $2(4.9)$ & 0 & $1(5.9)$ \\
\hline S-1 & $1(2.4)$ & $1(3.7)$ & 0 \\
\hline AMR & $1(2.4)$ & 0 & 0 \\
\hline DTX & $1(2.4)$ & 0 & 0 \\
\hline
\end{tabular}

Continuous variables are expressed as mean \pm standard deviation or median (interquartile range). Categorical variables are expressed as number (proportion). BSA, body surface area; PS, performance status; Hb, hemogulobin; Alb, albumin; NSAIDs, non-steroid anti-Inflammatory drugs; Non-Steroidal Anti-Inflammatory Drugs; Mg for purgative, Mg-contating medications for purgative; VNB, vinorelbine; PEM, pemetrexed; CPT-11, irinotecan; VP-16, etoposide; GEM, gemcitabine; AMR, amurubicin; DTX, docetaxel.

low-volume $\mathrm{Mg}+$ groups (median, $0.03 \mathrm{mg} / \mathrm{dl}$; interquartile range, -0.02 to $0.08 \mathrm{mg} / \mathrm{dl})(\mathrm{p}<0.001$ and $\mathrm{p}=0.0035$, respectively). The $\Delta \mathrm{CrCl}$ in the high-volume $\mathrm{Mg}$ - group (median, $16.29 \mathrm{ml} / \mathrm{min}$; interquartile range, 5.96 to $28.68 \mathrm{ml} / \mathrm{min}$ ) was also significantly higher than $\Delta \mathrm{CrCl}$ in the high-volume $\mathrm{Mg}+$ (median, $1.99 \mathrm{ml} / \mathrm{min}$; interquartile range, -3.79 to $8.56 \mathrm{ml} / \mathrm{min}$ ) and low-volume $\mathrm{Mg}+$ groups (median, $3.63 \mathrm{ml} / \mathrm{min}$; interquartile range -2.09 to $10.13 \mathrm{ml} / \mathrm{min})(\mathrm{p}<0.001$ and $\mathrm{p}=0.0316$, respectively). We also analyzed the $\mathrm{sCr}$ of each group at the end of subsequent cycles. The median values of $\mathrm{sCr}$ at the end of therapy in the high-volume $\mathrm{Mg}$ - and low-volume
$\mathrm{Mg}+$ groups were significantly increased compared with pre-sCr using the paired t-test and Wilcoxon matchedpairs signed-rank test $(\mathrm{p}<0.001$, and $\mathrm{p}=0.01$, respectively) (Additional file 2: Table S2).

\section{Univariate and multivariate analyses}

Table 5 shows the results of univariate and multivariate analyses. Only $\mathrm{Mg}$ infusion was a good predictor in univariate analysis $(\mathrm{p}<0.001)$. In multivariate analysis, $\mathrm{Mg}$ infusion was a significant good predictor of $\Delta \mathrm{CrCl}$ and low-volume hydration was a significant poor predictor of $\Delta \mathrm{CrCl}$ $(\mathrm{p}<0.001$ and $\mathrm{p}=0.001$, respectively). 
Table 3 The maximum grade of $\mathrm{sCr}$ increased and anorexia in each group

\begin{tabular}{|c|c|c|c|c|c|}
\hline Grade (n/\%) & $\begin{array}{l}\text { High-volume hydration } \\
\text { Mg- }(n=41)\end{array}$ & $\begin{array}{l}\text { High-volume hydration } \\
\qquad \mathrm{Mg}+(\mathrm{n}=27)\end{array}$ & $\begin{array}{c}\text { Low-volume hydration } \\
M g+(n=17)\end{array}$ & $\begin{array}{c}P \text { value }(\text { High } M g-\text { vs } \\
\text { High } \mathrm{Mg}+)\end{array}$ & $\begin{array}{c}P \text { value }(\text { High } M g-\text { vs } \\
\text { Low } \mathrm{Mg}+)\end{array}$ \\
\hline \multicolumn{6}{|c|}{$\mathrm{sCr}$} \\
\hline 0 & $0(0)$ & $1(3.7)$ & $1(5.9)$ & $<0.001$ & 0.002 \\
\hline 1 & 22 (53.6) & $26(96.3)$ & 15 (88.2) & & \\
\hline 2 & $17(41.5)$ & $0(0)$ & $1(5.9)$ & & \\
\hline 3 & $2(4.9)$ & $0(0)$ & $0(0)$ & & \\
\hline \multicolumn{6}{|c|}{ anorexia } \\
\hline$<2$ & $33(80.4)$ & $21(77.8)$ & $14(82.4)$ & 0.787 & 0.592 \\
\hline$\geq 2$ & $8(19.5)$ & $6(22.2)$ & $3(17.6)$ & & \\
\hline
\end{tabular}

The maximum grade of sCr increase was assessed using the Common Terminology Criteria for Adverse Events Version 4.0 (CTCAE v4.0).

\section{Discussion}

We found that renal function was significantly worse after cisplatin treatment in the high-volume $\mathrm{Mg}$ - group, and it also tended to worsen in the low-volume $\mathrm{Mg}+$ group. Only the high-volume $\mathrm{Mg}+$ group showed no significant alterations in renal function after cisplatin treatment. Multivariate analysis indicated that both the absence of $\mathrm{Mg}$ infusion and low-volume hydration were independent predictors for decreased renal function.

Mg supplementation and high-volume hydration may protect against the renal toxicity induced by cisplatin $[7,10,11]$. Although the detailed mechanism underlying this effect is not clear, recent reports have shown that the human organic cation transporter 2 (OCT2) is predominantly expressed in the human kidney at the basolateral membrane of renal proximal tubules [17]. In mice, Oct2 has been implicated in the cellular uptake of cisplatin, and Oct1/Oct2-deficient mice are protected from severe cisplatin-induced renal tubular damage [17]. In rats, $\mathrm{Mg}$ depletion may cause dehydration and upregulation of rat Oct2, which enhances renal accumulation of cisplatin and subsequent acute kidney injury [18]. In humans, a single nucleotide polymorphism in the OCT2 gene SLC22A2 (rs316019) has been associated with reduced cisplatin-induced nephrotoxicity and decreased gene expression [17]. In renal proximal tubule cells, the accumulation of cisplatin from the basolateral side is significantly greater than that from the apical side [19].
Thus, Mg supplementation was subsequently proposed to prevent $\mathrm{Mg}$ depletion and renal toxicity.

The volume of fluid for hydration is also an important factor that affects cisplatin-induced renal toxicity $[4,20,21]$. To our knowledge, no previous reports have compared renal toxicity between patients receiving high-volume $\mathrm{Mg}+$ and low-volume $\mathrm{Mg}+$ regimens. In the present multivariate analysis, both the volume of hydration and $\mathrm{Mg}$ infusion contributed to increased renal protection. These protocols were based on previous reports. Recent prospective studies have investigated low-volume hydration with $\mathrm{Mg}$ supplementation using hydration volumes of $1,500-2,500 \mathrm{ml}[2,14,15]$. In our study, the volumes of pre-hydration fluid administered were $1,800 \mathrm{ml}$ in the high- and $900 \mathrm{ml}$ in the low-volume $\mathrm{Mg}+$ groups. However, the volumes of post-hydration fluid administered within $4 \mathrm{~h}$ were almost similar between the high- and lowvolume $\mathrm{Mg}+$ regimens. The difference in volume may thus be an important factor related to the observed differences in renal toxicity. Hydration volume is related to osmolality and both serum and urinary concentrations of cisplatin. The extent of cisplatin induced nephrotoxic injury is dependent on both dose and cumulative cisplatin levels. Since high-volume hydration reduces the concentration of cisplatin compared to low-volume hydration, low plasma levels of cisplatin should reduce renal accumulation and decrease nephrotoxicity. In addition, high volume hydration decreases osmolality of blood resulting in decreased

Table 4 The comparison between pre and post $s \mathrm{Cr}$, and $\mathrm{CrCl}$ in each group

\begin{tabular}{|c|c|c|c|c|c|c|}
\hline & $\begin{array}{l}\text { Pre } s C r \\
(\mathrm{mg} / \mathrm{dl})\end{array}$ & $\begin{array}{l}\text { Post sCr } \\
\text { (mg/dl) }\end{array}$ & $P$ value & $\begin{array}{l}\text { Pre } \mathrm{CrCl} \\
(\mathrm{ml} / \mathrm{min})\end{array}$ & $\begin{array}{l}\text { Post CrCl } \\
\text { (ml/min) }\end{array}$ & $P$ value \\
\hline \multirow[t]{2}{*}{ High-volume hydration Mg- } & 0.75 & 0.92 & $<0.001$ & 78.88 & 65.99 & $<0.001$ \\
\hline & (0.64 to 0.92$)$ & (0.79 to 1.21$)$ & & (70.37 to 95.64) & (48.62 to 80.13$)$ & \\
\hline \multirow[t]{2}{*}{ High-volume hydration $\mathrm{Mg}+$} & 0.71 & 0.71 & 0.118 & 73.21 & 73.66 & 0.254 \\
\hline & (0.58 to 0.84 ) & (0.63 to 0.84$)$ & & (67.93 to 104.61$)$ & (64.39 to 100.65$)$ & \\
\hline \multirow[t]{2}{*}{ Low-volume hydration $\mathrm{Mg}+$} & 0.72 & 0.73 & 0.068 & 83.59 & 76.99 & 0.055 \\
\hline & (0.68 to 0.78$)$ & (0.70 to 0.85$)$ & & (72.51 to 103.63$)$ & (72.22 to 85.69 ) & \\
\hline
\end{tabular}

Median (interquartile range). $\mathrm{sCr}$, serum creatinine; $\mathrm{CrCl}$, creatinine clearance. 

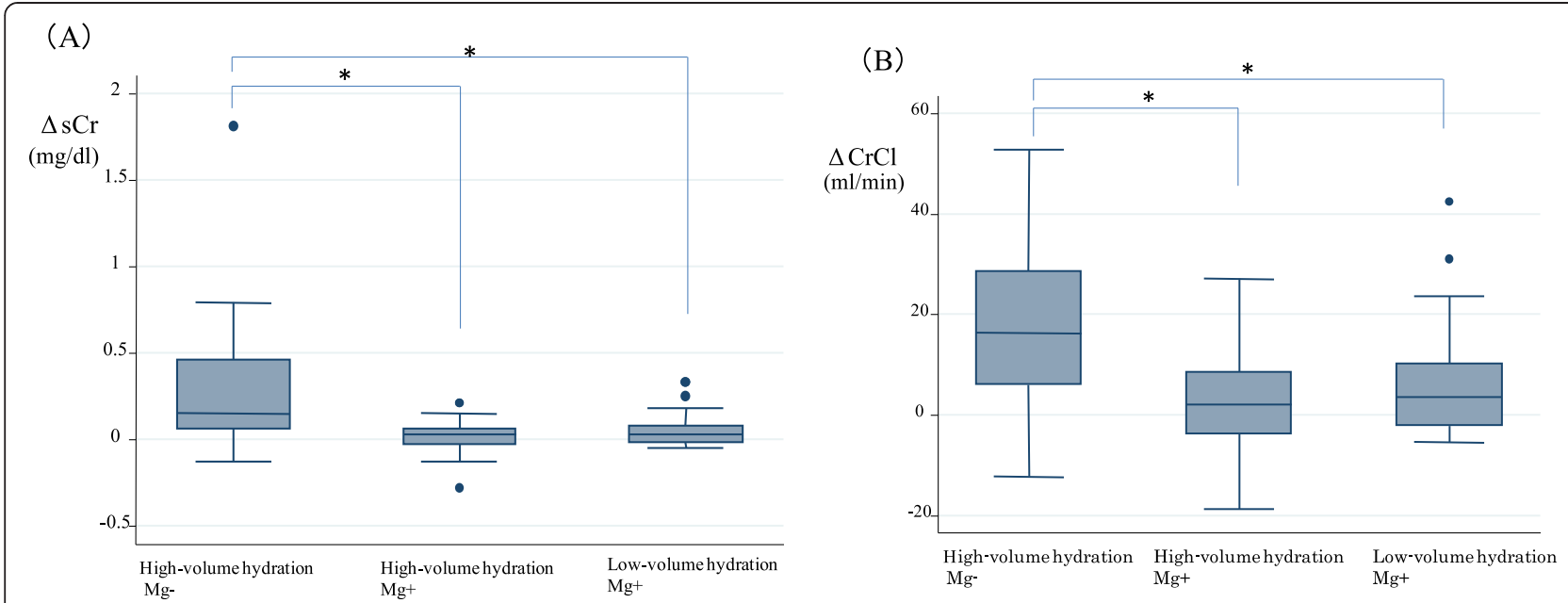

Figure 1 Comparisons of $\Delta \mathrm{sCr}(\mathrm{A})$ and $\Delta \mathrm{CrCl}$ (B) between treatment groups. The box plot provides information about the median, variability, and outliers of data distribution. The horizontal line within each box indicates the sample median. The plot consists of a box that extends from the 25th quartile to the 75th quartile. The box lines that extend from each end to the outermost data point that falls within the distances were computed as follows: 1st quartile +1.5 (interquartile range) and 3rd quartile +1.5 (interquartile range). Data points outside these computed ranges were considered outliers. sCr, serum creatinine; $\mathrm{CrCl}$, creatinine clearance, ${ }^{*} \mathrm{P}<0.05$.

secretion of antidiuretic hormone, decreased water reabsorption, more diluted urine, and increased urine output. It can thus be hypothesized that low urinary levels of cisplatin reduce renal accumulation of cisplatin and decrease nephrotoxicity. Therefore, the differences in osmolality in these two protocols may be related to the observed differences in nephrotoxicity.

One remaining question is whether $\mathrm{Mg}$ supplementation will also reduce the cytotoxic effects of cisplatin on tumor cells. Laboratory and clinical findings of $\mathrm{Mg}$ depletion have been observed in patients treated with high-dose cisplatin. Under low Mg conditions, tumor suppressors such as p21 and p27 are up-regulated, while oncogenes such as cyclins $\mathrm{D}$ and $\mathrm{E}$ are down-regulated [22]. It has also been suggested that there may be a correlation between the availability of $\mathrm{Mg}$ and vascular endothelial growth factor [23], and in particular that $\mathrm{Mg}$ depletion may suppress tumor cell proliferation and neoangiogenesis. Therefore, there could be some concern that Mg supplementation might promote tumor cell proliferation. However, previous prospective clinical trials and retrospective studies have indicated that $\mathrm{Mg}$ supplementation does not affect tumor response to cisplatin-based chemotherapy $[7,10,11]$. At any rate, the relationship between $\mathrm{Mg}$ depletion and tumor response to chemotherapy will require further investigation.

The present study has some limitations. First, this was a historical prospective cohort study and included a relatively small number of patients. Second, while some

Table 5 The predictive factors of $\Delta \mathrm{CrCl}$ according to univariate and multivariate analyses

\begin{tabular}{|c|c|c|c|c|}
\hline & \multicolumn{2}{|c|}{ Univariate analysis } & \multicolumn{2}{|c|}{ Maltivariate } \\
\hline & Coefficient $[95 \% \mathrm{Cl}]$ & $P$ value & Coefficient $[95 \% \mathrm{Cl}]$ & $P$ value \\
\hline Age (per 5 years) & $-1.15[-3.74$ to 1.43$]$ & 0.375 & $-1.58[-3.74$ to 0.58$]$ & 0.149 \\
\hline Female (vs male) & $5.03[-2.40$ to 12.46$]$ & 0.182 & $5.63[-1.64$ to 12.91$]$ & 0.127 \\
\hline PS 1 (vs PS 0) & $9.16[-1.37$ to 19.68$]$ & 0.087 & $3.34[-4.82$ to 11.49$]$ & 0.418 \\
\hline Serum albumin & $-3.53[-11.89$ to 4.84$]$ & 0.404 & $-1.28[-9.14$ to 6.59$]$ & 0.747 \\
\hline Cisplatin dose (per 5 mg/ml) & $-1.41[-1.57$ to 4.38$]$ & 0.348 & $1.24[-1.40$ to 3.90$]$ & 0.35 \\
\hline \multicolumn{5}{|l|}{ Regular use drug } \\
\hline NSAIDs & $7.63[-1.75$ to 17.02$]$ & 0.109 & $2.98[-5.25$ to 11.21$]$ & 0.473 \\
\hline Mg for purgative & $0.54[-7.25$ to 8.34$]$ & 0.89 & $-3.67[-10.10$ to 2.76$]$ & 0.259 \\
\hline Anorexia (grade 2 or more) & $-2.13[-9.51$ to 5.24$]$ & 0.566 & $2.19[-5.31$ to 9.70$]$ & 0.562 \\
\hline Mg infusion & $-14.73[-21.25$ to -8.21$]$ & $<0.001$ & $-15.28[-21.99$ to -8.57$]$ & $<0.001$ \\
\hline Low volume hydration & $-3.40[-11.33$ to 4.53$]$ & 0.396 & 22.31 [9.16 to 35.46$]$ & 0.001 \\
\hline
\end{tabular}

$\mathrm{Cl}$, confidential interval; PS, performance status; NSAIDs, non-steroid anti-Inflammatory drugs; Mg for purgative, Magnesium containing medications for purgative. 
14. Tiseo M, Martelli O, Mancuso A, Sormani MP, Bruzzi P, Di Salvia R, De Marinis F, Ardizzoni A: Short hydration regimen and nephrotoxicity of intermediate to high-dose cisplatin-based chemotherapy for outpatient treatment in lung cancer and mesothelioma. Tumori 2007, 93:138-144.

15. Hotta K, Takigawa N, Hisamoto-Sato A, Ichihara E, Kudo K, Uchida K, Yanase-Nakamura K, Tanaka H, Kato Y, Tabata M, Tanimoto M, Kiura K: Reappraisal of short-term low-volume hydration in cisplatin-based chemotherapy: results of a prospective feasibility study in advanced lung cancer in the Okayama Lung Cancer Study Group Trial 1002. Jpn J Clin Oncol 2013, 43:1115-1123.

16. von Elm E, Altman DG, Egger M, Pocock SJ, Gotzsche PC, Vandenbroucke JP: The Strengthening the Reporting of Observational Studies in Epidemiology (STROBE) statement: guidelines for reporting observational studies. Lancet 2007, 370:1453-1457.

17. Filipski KK, Mathijssen RH, Mikkelsen TS, Schinkel AH, Sparreboom A Contribution of organic cation transporter 2 (OCT2) to cisplatin-induced nephrotoxicity. Clin Pharmacol Ther 2009, 86:396-402.

18. Yokoo K, Murakami R, Matsuzaki T, Yoshitome K, Hamada A, Saito H: Enhanced renal accumulation of cisplatin via renal organic cation transporter deteriorates acute kidney injury in hypomagnesemic rats. Clin Exp Nephrol 2009, 13:578-584.

19. Endo T, Kimura O, Sakata M: Carrier-mediated uptake of cisplatin by the OK renal epithelial cell line. Toxicology 2000, 146:187-195.

20. Stewart DJ, Dulberg C, Molepo JM, Mikhael NZ, Montpetit VA, Redmond MD, Goel R: Factors affecting human autopsy kidney-cortex and kidney-medulla platinum concentrations after cisplatin administration. Cancer Chemother Pharmacol 1994, 34:14-22.

21. Stewart DJ, Dulberg CS, Mikhael NZ, Redmond MD, Montpetit VA, Goel R: Association of cisplatin nephrotoxicity with patient characteristics and cisplatin administration methods. Cancer Chemother Pharmacol 1997, 40:293-308.

22. Wolf Fl, Trapani V: Cell (patho)physiology of magnesium. Clin Sci (Lond) 2008, 114:27-35.

23. Wolf Fl, Cittadini AR, Maier JA: Magnesium and tumors: ally or foe? Cancer Treat Rev 2009, 35:378-382.

24. Konrad M, Schlingmann KP, Gudermann T: Insights into the molecular nature of magnesium homeostasis. Am J Physiol Renal Physiol 2004, 286:F599-605

doi:10.1186/2050-6511-15-70

Cite this article as: Oka et al:: Magnesium supplementation and high volume hydration reduce the renal toxicity caused by cisplatin-based chemotherapy in patients with lung cancer: a toxicity study. BMC Pharmacology and Toxicology 2014 15:70.

\section{Submit your next manuscript to BioMed Central and take full advantage of:}

- Convenient online submission

- Thorough peer review

- No space constraints or color figure charges

- Immediate publication on acceptance

- Inclusion in PubMed, CAS, Scopus and Google Scholar

- Research which is freely available for redistribution

Submit your manuscript at www.biomedcentral.com/submit
Ciomed Central 